\title{
Potential Impact of Rwanda Energy Plan on Carbon Emissions from Electricity Generation
}

\author{
Hakizimana Abdul Karim $^{1} \quad$ Umukunzi Carine $^{2}$ \\ School of Business \\ Nanjing University of Information Science and Technology, Nanjing, China \\ Email: abdulhkz250@gmail.com
}

\begin{abstract}
Energy is indispensable to economic \& social development and it improves lives. However, much of world's energy is being produced and consumed in ways that could not be sustained if technology were to remain constant and if general quantities were to rise significantly. This research weighs the potential results of Rwanda energy power plan 2023/2024 that encourage the use of more advanced and sustainable energy sources, Specific attention is paid to renewable energy. This research focused on examining the carbon emission emitted through electricity generation from different energy sources and investigate carbon emission avoidance when a national energy plan is implemented. The government of Rwanda, through its power sector, has very ambitious targets to achieve 512 MW installed power generation capacity, from its current 264 MW power generation, and have universal access $(100 \%)$ by $2023 / 24$. Business as usual (BAU) scenario is used to analyze future electricity generation and $\mathrm{CO}_{2}$ emissions reduction in 2020-2024. The scenarios show the sustainable potential of renewable technologies and advanced technologies such as hydropower that can generate a significant portion of electricity and minimize the carbon emissions from the power sector. This research found that when Rwanda energy plan is implemented, there will be a carbon emission reduction of $18.3 \%$. Hence, recommends policymakers and private sectors to invest in power energy production in Rwanda as there is a demand for electricity and business opportunities available in hydroelectricity production.
\end{abstract}

Keywords: Carbon emission, Renewable energy, Electricity generation, Rwanda

DOI: $10.7176 / \mathrm{JESD} / 12-6-01$

Publication date:March $31^{\text {st }} 2021$

\section{Introduction}

Energy is considered the main factor in wealth production and also an important factor in economic development [1]. The importance of energy to economic development is recognized almost everywhere. Global energy consumption is growing incredibly in parallel with population growth, industrialization and technological developments. The Energy Information Administration (EIA) expects global energy consumption to increase by almost 50\% between 2018 and 2020. The challenge is to develop technological concepts that will attain the maximum recovery of energy demanded. In $2000,80 \%$ of the world's demand for energy was met from fossil fuels, such as coal, petroleum, and natural gas [3], while the remaining $20 \%$ was obtained from other sources, such as hydro, nuclear, animal and vegetable wastes, wind, solar, geothermal and wood, among which hydro and nuclear are used more. In addition, the distribution of the world's known fossil fuel reserves are estimated to be on a petroleum equivalent basis, $68.3 \%$ coal, $15.5 \%$ petroleum, and $16.2 \%$ natural gas. Accordingly, the life of these, reserves are projected to be 41 years for petroleum, 62 years for natural gas, and 230 years for coal [4]. Rwanda is a small country in east Africa, it is sandwiched by Uganda, Burundi, Tanzania, and the Democratic Republic of Congo [5]. With a total area of $26338 \mathrm{~km} 2$, of which $94.7 \%$, land, the remaining $5.3 \%$ is occupied by water [7] and there are significant energy resources that have not yet been fully exploited. Demand for energy, and electricity in particular, is growing rapidly due to the social and economic development of the country.

In this sense, renewable energy sources seem to be one of the most effective and efficient solutions to growing demand and environmental challenges for sustainable development. Over the last two decades, the risk and reality of environmental degradation has become more evident, and mankind has increased the concentration of $\mathrm{CO} 2$ in the atmosphere. Co2 absorption has increased and is growing faster every day, so it has the average temperature on the planet. Despite growing evidence of the dangers of climate change, efforts to limit CO2 emissions, which are ineffective and do not exist in most countries, are sufficient. Taking into account the best available trends and scientific evidence, it is likely that humanity will have to reduce total emissions by at least $80 \%$ by 2050 .

Yet each day, emissions continue to grow, and the electricity sector is one of the major sources of the total global emissions [11]. In this study, Rwanda's energy strategy, electricity generation, and carbon emissions are described with an analysis of the general implication on the environment and economy. Many studies have developed a deep analysis of the carbon dioxide emissions reduction potential using renewable resources to generate the electricity needed for economic sustainability but No specific research has focused on the carbon emission from electricity generation in Rwanda and potential implications of the Rwanda energy sector strategic plan (ESSP). Currently, the total installed capacity to generate electricity in Rwanda is $264 \mathrm{Mw}$ from more than 
40 power plants, mainly hydro. Only $1.62 \%$ of the available capacity is imported while the rest is domestically generated [9].

This study investigates the potential impact of the power plan in the energy sector and analyse the change in the power structure and carbon emissions from the electricity to electrify Rwanda. This examination is novel in that it introduces a collaboration between economic development and inexhaustible power utilization to learn carbon emissions from each energy source in electricity generation the life cycle assessment of carbon emissions will be reviewed. To date, a number of life-cycle analysis studies have been carried out worldwide analysing the different aspects of product development and the potential impact of the product (from cradle to grave) on procurement, processing, production, use of raw materials and finally its removal [12]. LCA can be used to assess the environmental impact of electricity generation and allows producers to make better environmental decisions [11]. Between 1990 and 2008, global energy consumption increased by $40 \%$ in 2013, $68 \%$ of world energy comes from fossil fuels (i.e. coal, natural gas and oil), and electricity production accounts for $40 \%$ of world $\mathrm{CO} 2$ emissions [11,13]. Greenhouse gas emissions from energy production, such as CO2 emissions and CO2 emissions, have been the subject of numerous studies, which often play a key role in the development of greenhouse gas emission reduction strategies in the energy sector [14]. However, the extent to which these studies provide accurate, reliable and comparable information on their usefulness in long-term decision-making can be called into question.

In view of the growing concern about human action-genetic climate change, a sufficient understanding of the environmental impacts of greenhouse gas emissions from different energy production systems is needed [15]. For these emissions, each production method produces greenhouse gases, including $\mathrm{CO} 2$ to varying degrees, through construction, operation (including fuel supply) and dismantling.

\section{The Life Cycle Assessment of Carbon Emissions of Renewable Energy Technologies}

Greenhouse gas emissions shall be assessed and classified in accordance with the contribution of the following three phases of the lifecycle: (1) fuel supply (from fuel extraction to factory doors), (2) operation (operation and maintenance, including waste disposal) and (3) infrastructure (start-up and modernity) [15]. CO2-eq, or carbon dioxide equivalent (CO2-eq), is a standard unit for measuring greenhouse gas emissions. This is due to the expression of the effects of each different greenhouse gas on the amount of CO2 that would cause the same amount of warming. In this way, a carbon footprint consisting of several different greenhouse gases can be expressed as co2 eq. Hydropower includes solutions such as dams with reservoirs and next-generation plants. The first solution requires a dam to create a swimming pool and thus allows for equal jumps in electricity demand. Electricity generation from river flow systems depends on the amount of water flow and cannot be controlled. Greenhouse gas emissions throughout the lifecycle are reported for river co-service systems between 2 and $5 \mathrm{~kg}$ of $\mathrm{CO} 2$ eq/MWh and 11-20 kg of CO2-eq/MWh for dam reservoirs. An important aspect of hydropower with dam tanks are methane emissions from the anaerobic decomposition of flooded organic matter. These emissions depend on the local climate, the size of reservoirs, the depth of water, the type and quantity of flooded vegetation and the type of soil; therefore, significant differences in emission factors [18] can be observed.

For example, emission factors range from $0,35 \mathrm{~kg}$ OF CO2-eq/MWh in the Alpine regions to $30 \mathrm{~kg}$ of CO2eq/MWh in Finland and range up to $340 \mathrm{~kg}$ of $\mathrm{CO} 2 / \mathrm{MWh}$ in Brazil. But higher values were found when the reservoirs were located in tropical regions. Photovoltaic greenhouse gas emission factors showed high variability (one magnitude, 13-130 kg CO2-eq/MWh), mainly due to local conditions such as the power source used in production, panel carouselology and climatic conditions in which the panels were installed [19]. In addition, greenhouse gas emissions from PV technologies produced in different countries would differ from each other as electricity is used in the production process. A similar phenomenon can be explained by NOx and SO2 emissions [20]. Greenhouse gas emission factors from wind energy were found in PCA studies between 3 and $28 \mathrm{~kg}$ of CO2eq/ MWh, with system limits limited to wind turbines. In the present case, the main contributions related to the supply and construction of wind turbines. Therefore, the results were significantly influenced by the local electricity mix in which the turbines were produced and installed [21]. Onshore and offshore turbines may have similar emission factors as higher emissions during the construction phase can be offset by higher productivity of offshore turbines [22].

\subsection{Life Cycle Assessment of Carbon Emissions of Non-Renewable Energy Technologies}

For example, emission factors range from $0,35 \mathrm{~kg}$ OF CO2-eq/MWh in the Alpine regions to $30 \mathrm{~kg}$ of $\mathrm{CO} 2-$ eq/MWh in Finland and range up to $340 \mathrm{~kg}$ of $\mathrm{CO} 2 / \mathrm{MWh}$ in Brazil. But higher values were found when the reservoirs were located in tropical regions. Photovoltaic greenhouse gas emission factors showed high variability (one magnitude, 13-130 kg CO2-eq/MWh), mainly due to local conditions such as the power source used in production, panel carouselology and climatic conditions in which the panels were installed [19]. In addition, greenhouse gas emissions from PV technologies produced in different countries would differ from each other as electricity is used in the production process. A similar phenomenon can be explained by NOx and SO2 emissions [20]. Greenhouse gas emission factors from wind energy were found in PCA studies between 3 and $28 \mathrm{~kg}$ of CO2- 
eq/ MWh, with system limits limited to wind turbines. In the present case, the main contributions related to the supply and construction of wind turbines. Therefore, the results were significantly influenced by the local electricity mix in which the turbines were produced and installed [21]. Onshore and offshore turbines may have similar emission factors as higher emissions during the construction phase can be offset by higher productivity of offshore turbines [22].

\subsection{Methodology}

Energy is at the heart of Rwanda's economic and development plans. It supports all other sectors, including housing and urban construction, manufacturing, mining, tourism and its services. Therefore, a well-functioning energy sector and an effective precondition for achieving national targets. [42]

The Rwandan Energy Strategy aims to reach 2023/2024. In order to reduce the high dependence on diesel production, models of different production expansion systems have also been developed to ensure the use of different technologies for electricity generation in the Rwandan grid. The dates for the introduction of large shortterm projects were also used to determine the optimal selection of production in the country. Energy projects submitted in the short term and/or significantly far-reaching in the project development cycle (2020-2025). Model for estimating the life cycle of carbon emissions for energy production.

\begin{tabular}{lcccc} 
Table 1: Committed power plants (2020 - 2025) \\
\hline Power station & $\begin{array}{c}\text { Installed capacity } \\
\text { (Mw) }\end{array}$ & $\begin{array}{c}\text { Firm capacity } \\
\text { (Mw) }\end{array}$ & $\begin{array}{c}\text { Technology } \\
\text { type }\end{array}$ & Planned cod \\
\hline Hakan & 72 & 68.4 & peat & 2020 \\
Nyabarongo ii & 43.5 & 28.3 & hydro & 2024 \\
Rusumo & 26.7 & 25.4 & hydro & 2021 \\
Rusizi iii & 48.33 & 45.9 & hydro & 2025 \\
Symbion i & 50 & 47.5 & methane & 2023 \\
Others & 43.80 & 21.73 & mixt & 2024 \\
Total & $\mathbf{5 0 6 . 2 0 1 1}$ & $\mathbf{3 9 0 . 3 6}$ & n/a & $\mathbf{n} / \mathbf{a}$ \\
\hline
\end{tabular}

Data source: Rwanda Energy Group

The data in this study requires a complete set of data to illustrate the existing system as accurately as possible. A set of data used for all forms of energy used in the country and for all energy conversion processes (technologies), with the exception of imports and common regional production units. The energy supply technologies considered in the model include solar photovoltaics, hydropower, diesel, methane plants and peat plants. Some of the data collected from the bibliography report and the Rwandan Energy Group include energy production capacity (MW) by plant type, allowing us to determine energy production using technology. $\mathrm{CO} 2$ emissions have been used as an index to assess the carbon characteristics of energy production technologies in terms of global warming. The number of greenhouse gases attitted to generate pure $1 \mathrm{Gwh}$ electricity. This research used a bibliographic review to collect emission factors for all energy for electricity generation [1]. It is commonly known as GWh equivalent tones $(\mathrm{CO} 2 \mathrm{eq} / \mathrm{GWh})$. Direct emissions from actual and whole production chain, i.e. life cycle assessment (LCA), shall be taken into account. The aim of this study is to study the impact of the energy plan in Rwanda. The overall objective of this model is to test the reduction of carbon emissions in the electricity generation sector

$$
C O_{\# \text { emissions }}=\sum_{1} Q K * E F_{1}
$$

Where $\mathrm{CO} 2$ emissions are greenhouse gas emitted when generating electricity from all energy technologies used in Rwanda, such as hydropower, solar PV, peat, diesel, and methane gas. Every technique produces CO2 emissions in fluctuating amounts through the development and decommissioning. $\mathrm{K}$ is the energy type used to generate power in Rwanda, $Q K$ is referred to be the electricity units in GWh produced from a particular technology and $E F 1$ is the carbon emission factor, the average amount of tons of carbon dioxide emitted to produce $1 \mathrm{GWh}$ power. Table 2 . below shows the carbon emission factor per electricity generation technology.

Table 2. Carbon Emission from Electricity Generation.

\begin{tabular}{cccc}
\hline Technology & Mean & $\begin{array}{c}\text { Low } \\
\text { Tonnes } \mathbf{C O}_{2} \mathbf{e q} / \mathbf{G w h}\end{array}$ & High \\
\hline Diesel/oil & & 547 & 935 \\
Coal /peat & 733 & 756 & 1310 \\
Solar pv & 888 & 13 & 731 \\
Hydropower & 85 & 2 & 237 \\
Methane gas & 26 & 362 & 891 \\
\hline & 499 & Data source: World nuclear Association
\end{tabular}


The key issue to address is to analyse the current carbon emissions from electricity generation and the potential carbon emission reduction from the Rwanda energy expansion power plan. The analysis of the power plan sector consists of 2 scenarios.

Table 3. Scenario Description

\begin{tabular}{|c|c|}
\hline Scenarios & Description \\
\hline $\mathrm{BAU}$ & $\begin{array}{l}\text { BAU scenario starts from } 2020 \text { as the base year. } \\
\text { The energy system of the base year } 2020 \text { will be modeled using the } \\
\text { current power structure and reported data, then existing energy } \\
\text { installed capactity trends will be projected till the end of the planning } \\
\text { period which is } 2024 \text {. The BAU scenario includes projections for } \\
\text { electricity generation and } \mathrm{CO}_{2} \text { emissions. }\end{array}$ \\
\hline Scenario 1 & $\begin{array}{l}\text { Analyze the current power structure and carbon emissions emitted } \\
\text { through electricity generation from each energy source }\end{array}$ \\
\hline Scenario 2 & $\begin{array}{c}\text { Analyze Rwanda power plan } 2024 \text { planned installed capacity and } \\
\text { projected electricity generations to calculate carbon emissions using } \\
\text { the base year } 2020 \text { power system to measure the carbon emission } \\
\text { avoided. }\end{array}$ \\
\hline
\end{tabular}

To analyse both scenarios and examine the potential carbon emission avoidance from 2020 to 2024 according to the national energy plan, we compare total carbon emissions from both years to get results in overall carbon emission reduction for climate change and lower global warming using the following formula.

$$
\mathrm{CO}_{2} \text { emissions }=\text { scenario } 2-\text { scenario } 1
$$

\subsection{Findings and Discussions}

\subsection{Electricity Generation of BAU Scenario}

According to the African bank of development report ${ }^{[36]}$. The electricity demand in the Rwanda power sector is expected to increase by $9 \%$ by 2023 . The power plan is developed in order to meet the forecasted electricity demand. In the BAU scenario, the electricity supply in Rwanda has been increasing, and pivot on the hydropower energy (see Fig 1). From 2020 total electricity generation, there is a $698.53 \mathrm{GWh}$ increase in 2024. Hydropower, methane gas, peat, solar PV, and diesel and hydropower plants are the major contributions to generate electricity and accounted for $38 \%, 37 \%, 10.5 \%, 1.10 \%$, and $12.1 \%$ in total electricity generation, respectively. The installed capacity in Rwanda would increase from $264 \mathrm{MW}$ with $218 \mathrm{MW}$ nominal capacity in 2020 to $404 \mathrm{MW}$ in 2024 as presented in table 5 . In the BAU scenario

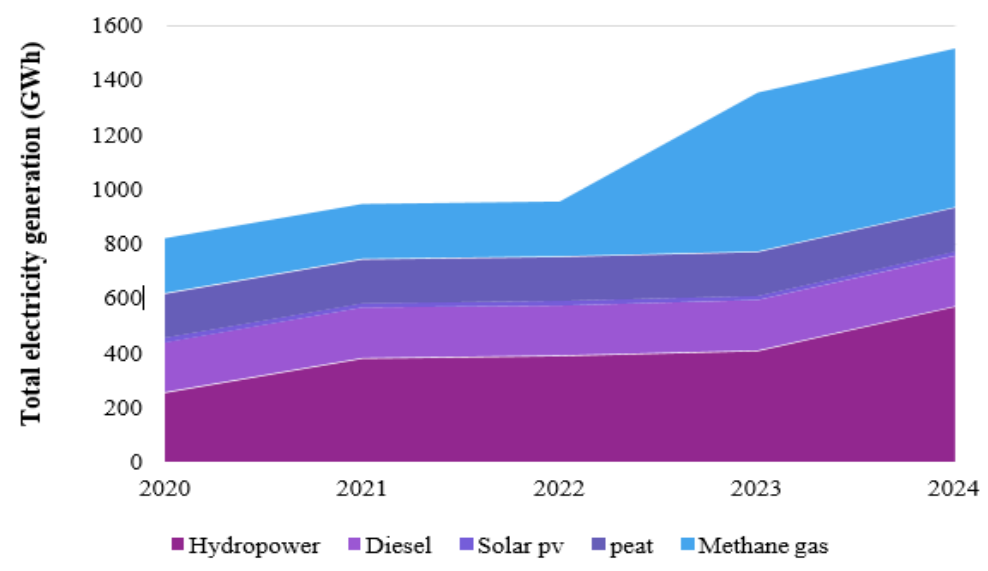

Figure 1. Total electricity supply in the BAU scenario in Rwanda.

Data source: African Development bank 
Table 4. Rwanda's Power Installed Capacity in the BAU Scenario.

\begin{tabular}{lccccc}
\hline Energy sources & $\mathbf{2 0 2 0}$ & $\mathbf{2 0 2 1}$ & $\mathbf{2 0 2 2}$ & $\mathbf{2 0 2 3}$ & $\mathbf{2 0 2 4}$ \\
\hline Hydropower & 72 & 108 & 110 & 115 & 161 \\
Diesel & 59 & 59 & 59 & 59 & 59 \\
Solar Pv & 12 & 12 & 12 & 59 & 59 \\
Peat & 95 & 95 & 95 & 95 & 95 \\
Methane gas & 26 & 26 & 26 & 76 & 76 \\
Total & 264 & 300 & 302 & 358 & 404 \\
\hline \multicolumn{5}{c}{ Data source: Ministry of Infrastructure in Rwanda }
\end{tabular}

4.2 pact of ESSP on Carbon Emissions in Scenario 1

In scenario 1 , the electricity generation will increase by using advanced and renewable energy technologies such as hydropower. Still, also, there is a significant increase in electricity generated from diesel, peat, and methane technologies. In the BAU scenario 1, CO2 emission from the power sector was accounted for 717,040.4 tCO2eq. Peat accounting for $36.8 \%$, diesel $35 \%$, methane gas $26 \%$, solar PV $0.36 \%$, and hydropower for $1.69 \%$ of the total $\mathrm{CO} 2$ emissions.

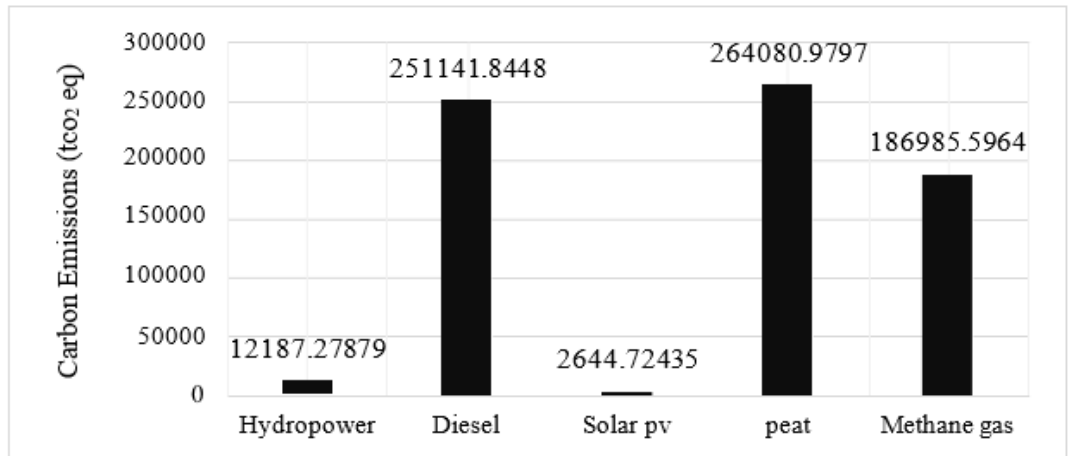

Figure 2. Scenario 1 carbon emissions from Rwanda power sector

Data source: African Development bank

4.3 Impact of ESSP on carbon emissions in Scenario 2

As a developing country, Rwanda has a great challenge to the impact of climate change. Rwandan government formulated plans to reduce $\mathrm{CO}_{2}$ emissions in all sectors, including power and energy against climate change. The following plans are approved by the UN sustainable development goals (SDGs) and other regional agreements. In this scenario, the electricity generation from RE plants is expected to increase from a total of $816.06 \mathrm{GWh}$ in 2020 to $1514.58 \mathrm{GWh}$ in 2024 . Renewable energy will contribute to the total energy supply of $48.12 \%$ in 2024 , and total $\mathrm{co}_{2}$ emission in this scenario will be $585372.78 \mathrm{tCO}_{2}$-eq.

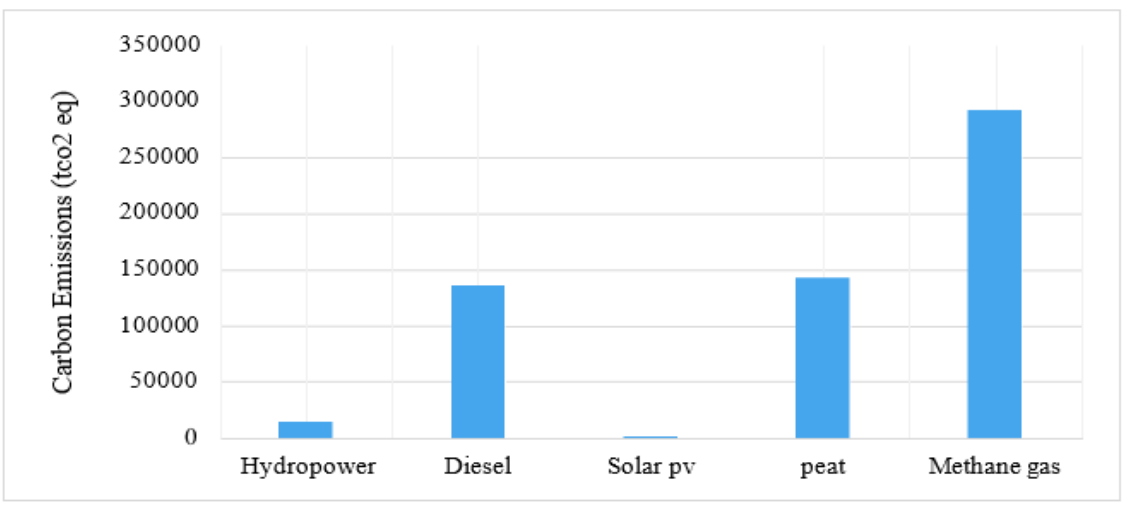

Figure 3. Scenario 2 carbon emissions from Rwanda power sector

Data source: African Development bank

From the BAU scenario after implementation of the power plan, the reduction will be on the peak of $\mathrm{CO}_{2}$ reduction expected, electricity generated is about $1514.58 \mathrm{GWh}$ and renewable energy contributing $48.12 \%(37.5 \%$, 
$10.57 \%$ from hydropower and solar PV). Total carbon emission avoided would be $-131667.634 \mathrm{tco}_{2}$ eq as a result of using more advanced renewable technologies to generate electricity. Therefore, in the scenario, $\mathrm{CO}_{2}$ emission will be lower $18.36 \%$ in 2024 than 2020 Figure 4. Illustrates total $\mathrm{CO}_{2}$ emission comparison between scenario 2 and scenario 1.

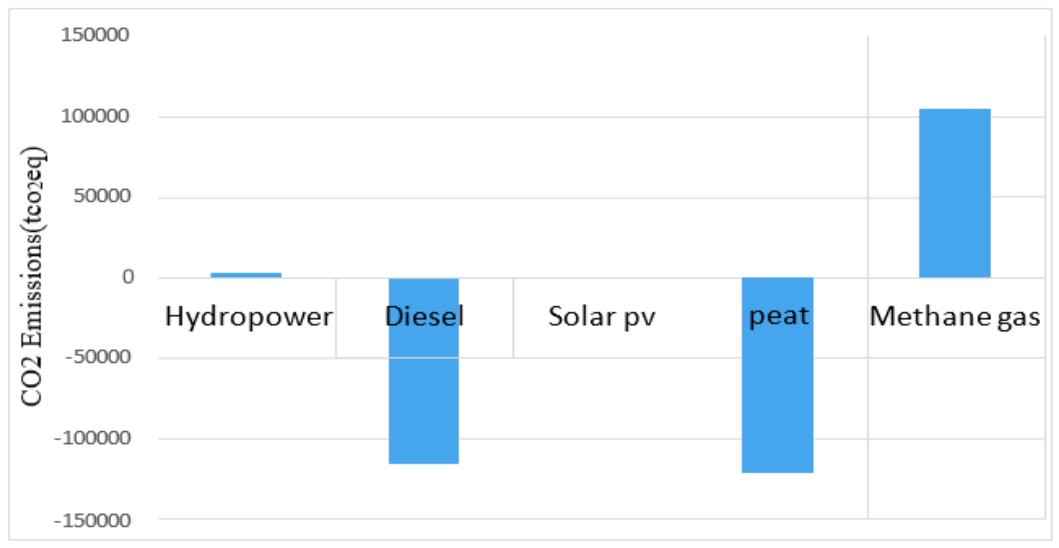

Figure 5. BAU scenario total carbon emissions Avoided (scenario 2- scenario 1)

4.4 Sensitivity Analysis

To examine issues relating to uncertainties in the model structure used to obtain the results, a sensitivity analysis was investigated, to measure the impacts of fluctuations in carbon emissions from power production aiming to acquire more reliable results. For sensitivity analysis, this research calculated carbon emission from electricity generation using the lowest carbon emission factors $(\mathrm{CO} 2 \mathrm{eq} / \mathrm{GWh})$ from each energy source to examine their sensitivity to the carbon emissions avoided results of the BAU scenario between 2020-2024 power structure. For each technology, carbon emission factors can range from low to high depending on the transformation efficiency [43]. It is noted that when the energy transformation efficiency is improved, except the carbon emission reduction from electricity generation. We assumed the lowest carbon emission factors from each energy source, and the results of sensitivity analysis are shown in the table below.

Table 5. Sensitivity Analysis

\begin{tabular}{lcc}
\hline Energy sources & $\mathbf{C O}_{2}-\mathbf{e q} / \mathbf{g w h}$ & $\mathbf{t} \mathbf{C O}_{\mathbf{2}}-\mathbf{e q}$ \\
\hline Hydropower & 2 & 199.9121703 \\
Diesel & 547 & -86435.15551 \\
Solar pv & 13 & -186.5489575 \\
Peat & 756 & -103689.2989 \\
Methane gas & 362 & 75862.79413 \\
$\quad$ Total & N/A & $-\mathbf{1 1 4 2 4 8 . 2 9 7 1}$ \\
\hline
\end{tabular}

From the BAU scenario after implementation of the power plan, sensitivity analysis results show that total carbon emission reduction would be -114248.29 t CO2-eq, which indicates a significant carbon emission avoided in power generation in 2024. Conservation, and environmental improvements as a result of reducing greenhouse gases (especially $\mathrm{CO} 2$ ) emitted as a result of thermal generation. Rwanda can achieve many technical and ecological benefits from applying smart grid technologies, especially in the field of increased electricity generation from wind and solar energy sources as well as hydroelectricity.

\subsection{Conclusions and Policy Recommendations}

This research set out to evaluate the potential impact of energy power plan in Rwanda, discussed Rwanda's energy plan and examined the impact of renewable energy to electrify Rwanda and most importantly reduction of the carbon emission from electricity generation. The potential of advanced and renewable energy technologies is very promising in the long-term electricity planning. Rwanda's energy sector strategic plan will reduce $\mathrm{CO}_{2}$ emission by $18.36 \%$ when compared with BAU scenario carbon emissions in 2020 . In conclusion, Renewable energy and advanced technologies take advantage of reduced $\mathrm{CO}_{2}$ emissions at a considerable cost.

Economically, business opportunities are available for the private sector in hydropower, and solar energy for energy production, prospecting, and exploitation since the power plan encourages the development of more renewable source power plants.

Strong evidence indicates that renewable sources, mostly hydropower could provide significant clean and 
reliable electricity production in Rwanda. Many promising sites exist, distributed throughout the country. Considering the need for energy development and available hydropower resources, our analysis suggests several possible policy recommendations.

Due to the difficulty of building energy transmission in Rwanda, it is advisable to encourage small hydropower use in off-grid systems. Investments should be made to develop the necessary support expertise for small hydropower technologies, including expertise for community-based micro-grids and training for plant maintenance to reduce operational cost.

Small hydropower remains a niche business worldwide. Policies should be considered to attract investors willing to design and manufacture some hydropower plant components in Rwanda. This would allow solutions to be customized for Rwandan conditions.

\section{References}

[1] Yüksel I. Hydropower for sustainable water and energy development [J]. Renewable and Sustainable Energy Reviews, 2010, 14 (1): 462-469.

[2] IEA. EIA projects nearly 50\% increase in world energy usage by 2050 , led by growth in Asia - Today in Energy [EB/OL].U.S. Energy Information Administration (EIA), 2019-2021, 77 (6): 200-210. https://www.eia.gov/todayinenergy/detail.php?id=41433.

[3] Dincer I. Renewable energy and sustainable development: A crucial review [J]. Renewable and Sustainable Energy Reviews, 2000, 4 (1): 157-175.

[4] Jos G..J. Olivier, Greet Janssens - Maenhout J A H W P, Góralczyk M, Hudson C R. Trends in global $\mathrm{CO}_{2}$ emissions 2012[EB/OL]. World Energy Council 2016, 75 (5): 205-211. https://www.worldenergy.org/wpcontent/uploads/2016/10/World-Energy-Resources_SummaryReport_2016.10.03.pdf.

[5] Atlas W. Where is Rwanda? [R]. 2017.

[6] Rwanda $\mathrm{n}$ i of s. NISR [EB/OL]. 2018, http://www.statistics.gov.rw/

[7] Bank W. Republic of Rwanda Ministry of Agriculture and Animal Resources (MINAGRI) Rural Sector Support Project (RSSP3) [EB/OL]. http://documents.worldbank.org/curated/en/

[8] REG. Investment Information Pack, Investment Opportunities in Hydropower Sector-Rwanda [EB/OL].2018, http://reg.rw/index.php/investments/opportunities.

[9] REG.LCPDP_REPORT_converted [EB/OL]. http://www.reg.rw/fileadmin/user_upload/LCPDP_REPORT_June_2019.pdf\#.

[10] Pratt R G, Balducci P, Gerkensmeyer C. The smart grid: an estimation of the energy and CO2 benefits [J]. PNNL-19112, available at: http://energyenvironment.pnnl.gov/, 2010, 18 (3): 1-172.

[11] Góralczyk M. Life-cycle assessment in the renewable energy sector [J]. Applied Energy, 2003, 75 (4): $205-$ 211.

[12] Varun, bhat I K, Prakash R. LCA of renewable energy for electricity generation systems-A review [J]. Renewable and Sustainable Energy Reviews, 2009, 13 (5): 1067-1073.

[13] Turconi R, Boldrin A, Astrup T. Life cycle assessment (LCA) of electricity generation technologies: overview , comparability and limitations[J]. 2013, 35 (2): 28-35.

[14] HUDSON C R, BADIRU A B. Energy systems [J]. Operations Research Applications, 2008, 5 (1): 5-30.

[15] Hondo H. Life cycle GHG emission analysis of power generation systems: Japanese case [J]. 2005,30 (3): 2042-2056.

[16] ReporT W N A. Comparison of Lifecycle Greenhouse Gas Emissions of Various Electricity Generation Sources [J]. 2014, 80 (4): 90-101.

[17] Nomura N, Inaba A, Tonooka Y. Life-cycle emission of oxidic gases from power- generation systems [J]. 2001, 68 (2): 215-227.

[18] Dones R, Heck T. Greenhouse Gas Emissions from Energy Systems, Comparison and Overview [J]. 2004, 3 (4): 77-95.

[19]Fthenakis V, Alsema E. Photovoltaics Energy Payback Times, Greenhouse Gas Emissions and External Costs: 2004-early 2005 Status [J]. 2006, 18 (2): 275-280. .

[20] KrauteR S, RU R. Considerations for the calculation of greenhouse gas reduction by photovoltaic solar energy [J]. 2004, 29 (2): 345-355.

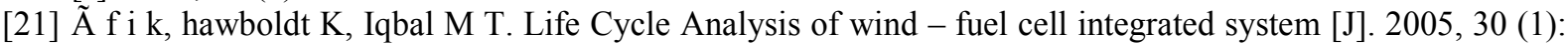
$157-177$.

[22] Pehnt M. Dynamic life cycle assessment (LCA) of renewable energy technologies [J]. 2006, 31 (4): 55-71.

[23] May J R, Brennan D J. fossil energy options [J]. 2003, 23 (1): 18-25.

[24] Uchiyama Y, Gagnon L. Life-cycle assessment of electricity generation options: The status of research [J]. 2002, 30 (1): 1267-1278. .

[25] Green O, Studies G. OECD Green Growth Studies [J]. Director, 2012, 22 (2): 104-106.

[26] Vander Plas R J. Biomass Energy Strategy (Best), Rwanda[R]. 2009. 
[27] Munyaneza, J., Wakeel, M., and Chen B. Overview of Rwanda energy sector: from energy shortage to sufficiency. [J]. Energy Procedia, 2016, 104 (6): 215-220.

[28] Esiara K. Dispute Delays Rwanda Power Project by 3 years [N]. The East African, 2014.

[29] Landi, M., Sovacool, B. K., and Eidsness J. Cooking with gas: policy lessons from Rwanda's National Domestic Biogas Program (NDBP).[J]. Energy Sustain. Dev., 2013, 17 (3): 347-356.

[30] Rakotojaona L. Domestic Biogas Development in Developing Countries [J]. 2013, 63 (2): 112-125.

[31] Sinaruguliye, J. C., and Hategekimana J B. Biogas Development Scenarios Towards 2020 in Rwanda: The Contribution to the Energy Sector and Socio-Economic and Environmental Impacts.[D]. Master's thesis, University of Gavle Sweden, 2013.

[32] MININFRA. Peat Energy [EB/OL].2014, http://www.mininfra.gov.rw/index.php?id=82.

[33] CR (Construction R. Rwanda Launches First Peat-Fired Power Plant in Africa.[ EB/OL].2017, https://constructionreviewonline.com/2017/04/rwanda-launches-first-peat-fired-power-plant-in-africa/.

[34] Esi-Africa. Rwanda Welcomes Africa's Peat to Power Plant. Africa’s Power J.[R]. 2014.

[35] Remington C. Project Kivu Watt Generates Electricity from Rwanda's Explosives Lake Kivu, Revolt [EB/OL].2013, http://blogs.worldwatch.org/revolt/project-kivuwatt-generates- electricity-from-rwandasexplosive-lake-kivu-2/.

[36] AFDB. Rwanda-Scaling up Energy Access Project.[R]. 2013.

[37] Rwanda energy group. Power generation[R].2020.

[38] MINIFRA. Generation [EB/OL].2019, https://www.mininfra.gov.rw/index.php?id=317.

[39] MINIFRA. Republic of Rwanda ministry of infrastructure [J]. 2018, 66 (3): 106-115.

[40] Malunda D. Report for the African Centre for Economic Transformation (ACET) Rwanda: Case Study on Economic Transformation [EB/OL]. Institute of Policy Analysis and Research - Rwanda (IPAR), 2012, 44 (2): 1-64. http://www.afdb.org/fileadmin/uploads/afdb/Documents/Project-and-Operations/Rwanda_Leveraging_Capital_Markets_for_Small_and_Medium_Enterprise_Financing.pdf.

[41] MINICOFIN. The Republic of Rwanda economic development and poverty reduction strategy[R]. 2013.

[42] MINIFRA. Peat Energy [EB/OL].2014, http://www.mininfra.gov.rw/index.php?id=82

[43] Gao T, li a, meng f. Research on Data Stream Clustering Based on FCM Algorithm1 [EB/OL]. Procedia Computer Science, 2017, 122 (7): 595-602. https://doi.org/10.1016/j.procs.2017.11.411.

\section{Acknowledgment}

This study has benefited greatly from the constructive comments and suggestions that I have received from my supervisor Wang Feng (汪 峰) I fully acknowledge your enormous contribution 